\title{
Analysis of Democratic Construction in China and Internet
}

\author{
Guoyou Zhang ${ }^{1,2}$ and Xueru Yin ${ }^{2}$ \\ ${ }^{1}$ School of Finance and Economics of Xi'an Jiaotong University, Xi'an ,China,710061 \\ ${ }^{2}$ Department of Economy \& Trade of Tongling University, Tongling, China,244000
}

\begin{abstract}
As the popularization of Internet in every aspects of modern life, the development of democratic construction faces both opportunity and challenge in information age. This article analyzes the current situation of democratic construction, and discusses the influence of Internet, then brings up the method to discriminate cyber public opinion to enhance democratic construction. Finally it elaborates how to achieve democratic construction via Internet to promote democracy in the society.
\end{abstract}

Keywords-internet; democratic construction; democracy

\section{INTRODUCTION}

In human history, the development trace of democracy has always been one of the most important issues that highly discussed in political sciences study. Democracy is also the one concept that been used most frequently in politics. Apparently, the development of political democracy has became one of the crucial criteria to evaluate the advance of one nation and society, especially in today's modern society where economic growth has boosted so dramatically. Ever since modern times, the democratic construction improved tremendously in China, however, deep-stated problems still existing. By applying the platform of Internet, the existing issues of democratic construction can be solved better in modern society. As the development and popularization of cyber technology, Internet changed the way of people's thinking, communicating, and behaving in a great deal. And the changes impact many aspects of the democratic construction in China.

\section{IMPACT OF CHINESE DEMOCRATIC CONSTRUCTION LED BY THE DEVELOPMENT OF INTERNET}

The Impact of Chinese democratic construction that led by the development of Internet show in various sides, it includes the positive side that can promote the development of democracy, as well as the negative one that obstruct the footstep. Cyberspace not only provides the advanced technology, operation platform, but also changes the thinking pattern and behaviors in great deal by achieve its popularization.

\section{A. Internet Provides New Channels for Democratic Construction.}

Democratic construction in China is facing both opportunities and challenges. Information and communication technology influenced democratic construction greatly in an active and positive way. It created the atmosphere to discuses democratic issues in open space, built a non-obstruction platform for democratic construction, expended the inspection extent for citizen to exam and gave the opportunities to open up the affairs in party and government to public. The implement of Internet technology, the improvement of citizen's awareness and emerging Internet politics all provide a new path to democratic construction inside the party by applying the information technology. Therefore, to unleash the positive effect of Internet in democratic construction, we should promote the democratic construction as the center of effect, focus on both of "free environment" and "strict term" in cyberspace to enhance cyber construction.

Internet opens up new channels and increases the possible choices for democratic construction. After two decades' development in China, Internet has already become an essential part of people's daily life. It is obvious that Internet is playing a curtail role in influent and push the society to go forward. Examples can be seen as "the General Secretary faces netizen to communicate with each other" ; the public request for the Bill of two Conferences (i.e. the National People's Congress and the Chinese Political Consultative Conference) and its non-trimmed online broadcast; the heated discussion on Internet about the events like Jiaxiang Lin(the chief of marine board who is a suspect for a crime of misdemeanor), Jiugen Zhou(Head of Real Estate Administrative Bureau Nan Jing City who is condemned bribery crime for 11 years), villas of leading cadre, as well as the civil servants' public Bills of investigation trip abroad.

Though out all these years, the basic essence and capability of citizens have improved in great deal, the optimize allocation of resources set the intellective foundation of democratic construction that using Internet.

Network politics supplies the soil for applying Internet on democratic construction after it makes the first appearance, for the specific politic environment nurtures corresponding form of democracy. The natural advantages of Internet, such as freedom, equality, individuality, interaction proven to have big affects on the characteristic, organization, and target of political process, political actor, and political system. And that is formed the Internet politics with the feature of substantivity, equality, convenience and low cost. Under this soft environment of political civilization and culture, the procedure, awareness, and system of democracy have been created and developed. The combination of deliberative democracy, participatory democracy, and representative democracy formed the implement of democracy, and grassroots-layer begins to join with social elite to participate in the discussion of political life.

In the society of network politics, the public participation of politic break the restriction of traditional political form, the reciprocity between inner-Party democracy and social democracy developed a new stage and space under the guidance of scientific development path, Internet politic is already a important field in socialistic and political development. 


\section{B. Internet Provide New Platform and Technology for Democratic Participation}

Democratic participation includes the access and public of masses' information, the participation for decision making and election of citizen. The famous scholar of mass communication Marshall McLuhan (1911-1980) predicted last central when television industry developed in large scale that as the movement of information, politics will tend to develop the civil involved central government policy and drift away from voter representative politic. It was only focus on the development of television then, but now the advance of Internet make tendency irreversible, simple because it provides the technical supportability for civil participation.

First of all, the new channel has been given to assure the unrestricted access and public information. Secondly, Internet provides the platform for masses to take part in decision making. At last, network supplies new technology for democratic election.

\section{Internet Weakens the Inequality in Reality and Strengths the Idea of Pursuing Fairness}

Although people been given equal political rights and social state by law, the unbalancedness brought by development of social, politic, economy prevent everyone from the total equality when excises personal rights. In the virtual space, the inequality in reality is weakening so that it allows people to see more fairness they cannot necessarily look for in real life. Firstly, the openness and equality between Internet users decide that in the virtual space everyone enjoys total fair services. Secondly, virtuality of Internet makes "societal state" equal among users. You can browse a same web page with the state leaders, and check stock market trends with worlds richest.

The equality in virtual space arouses the stronger will of pursuing fairness in reality. Nowadays, the increasing need of pursuing fairness of political and social state in real life is valued more and more, despite the difference of economy, culture background, occupation, people hope to gain the same treatment of equal political state and rights to participate political life in cyberspace. Recently, politic is discussed much more by citizens; the increasingly noticed unfairness, the reach out to each other, the protection via law to defense the civil right are all the manifestation of pursuing equal political status.

\section{The Increasingly "Digital Gap" that Brought by Internet Development Enlarges Information Hegemony and Class Discrepancy}

Compare to the democracy and equality in virtual space, the "digital gap" between conditional Internet user and non-conditional Internet user is grow bigger and bigger in real life. Besides, the huge gap also obstructs the development of political democracy. To begin with, the expending "digital gap” might create new "democratic gap'. Some who hold a negative view think that digital technique brings the new unbalance of rights and wealth, these factors raise a bigger gap to the existing "digital gap" between those who process rich information and those who only get little information. And it benefits social elites more during the procedure while cause lost to lower orders. Meanwhile, the digital gap effect political democracy in society and create "democratic gap". Along with the appearance and enlarge of gap between the rich and the poor, some of the elites start to organize their own community that consist of several similar social state member by using their power in society and defense their interest by all means. However, people at the bottom usually with less political awareness. This situation makes the society more unfair and lead to new issues to the development of democracy. Next, in the world wide, the American hegemony and English hegemony are particularly severe. America develops the most popularization of Internet application, and among $90 \%$ of information is spread in English though out the whole Internet system. Therefore, the voice coming from America and western countries are very influential that no other region can compete with. At the same time, the democracy spread on Internet is also the democracy form America and western countries. So the information hegemony put obstruction and reverses effects on other non-English speaking countries, and cause difficulties for them to carry out their own democracy via Internet. Furthermore, this problem is particularly serious when it comes to the socialism country like China.

\section{E. Virtual and Anonymous Information in Cyberspace Set a New Challenge for Political Democracy Development}

Virtuality and anonymity is the most distinguish feature of the publication of online information. Due to this reason, Internet became one of the thrusters that promote the development of democracy and social equality. However, it also leads to the irresponsible during the process of passing the information, and cause negative effects on social democratic development. Besides, network environment intervened by some misleading or extreme information that mingled with other massive network information which can be both good and evil. In this case, the information would be manipulated by individual or group with agenda. Under the circumstance of liberalization and pluralism in cyberspace, the misleading or extreme information caused by different, even incompatible opinions conflict to each other will exist due to massive amount of unstrained information rush into Internet in a dispersive way. When a huge amount of misleading or extreme information enters Internet, some residents tend to trapped into misunderstanding. These opinions claim to a different values of world, of life, split people's ideology, and cause the instability of the society, eventual threat to free development of political democracy.

\section{THE RIGHT WAY TO SEE CYBER PUBLIC OPINION AND} BOOST DEMOCRATIC CONSTRUCTION IN CHINA.

In the process of modernization and informatization in China, Internet became more and more important as a public opinion channel. How to treat cyber public opinion is one impending question that needs to be answer both theoretically and practically.

\section{A. Value of Cyber Public Opinion}

Cyber public opinion becomes increasingly crucial. From the aspect of netizen, Internet user is a very important part of group. The speed of netizen growth is rapid. Until the end of 2011, there are more than five hundred million netizen, that take $40 \%$ of total population in China, and with some developed areas, the proportion are even higher. From network aspect, Internet is already developed as a significant media. After the huge jump of Chinese Internet industry, cyberspace turned into a vital platform for netizen to discuss public affairs, express personal ideas and supervision by public opinion. Each influential event inside or outside the country can cause strong response and drastic discussion. In 
the popular website like People's Net and www.xinhuanet.com, the strong response and drastic discussion posted by Internet user everyday arouse big public influence. The influence, social state, social recognition and report ability of big event preformed by Chinese Internet media all prove that it process a vital part in China. From the public will aspect, cyber public opinion is a mirror of reality, things happen in real life often reflected online. The hot topic in virtual space is also the hot topic in present world. For example, the topic been discussed online like combat corruption and build a clean government, social equality, gap between the rich and the poor, and unreasonable service is also the issues going on in present world.

China is a socialist state that people people as the masters of the country, so listen and understand to its people, comply with people' opinion is the immanent demands of Chinese government. There are many ways of express public opinion, and any type of passing the message should be respected. Of course, the official way of convey public will is the traditional process like National People's Congress and Chinese People's Political Consultative Committee, but the unconventional method that develops day by day like cyber public opinion should not be ignored. Especially for lower group of the society, this new channel is more important and helpful. Although Internet is a virtual world, but netizen still live in the reality, and behind every nickname and IP address, there are real people to match along with. Therefore, in some sort way, cyber public opinion is actually an authentic public will with lower cost, faster spread speed, shorter amount of time and more information. Thus, government should make the good use of Internet, really listen and accept public inspection.

\section{B. Discrimination of Cyber Public Opinion}

Cyber public opinion possesses the feature of universality, authenticity, timeliness and complexity. And for these feature, we need to analysis and discriminate it in order to promote the development of democratic construction.

The universality of cyber public opinion is reflected in every aspect of class, region, and industry and so on. Take website as an example, one specific website may have its own tendency, while when take the information from many other sites into consideration, the containing of Internet information will manifest. No matter what type of culture, ideology, values, living criteria and moral standard can find a space in the virtual world. For this reason, opinion and thoughts coming from Internet are comprehensive and diversiform. While, there are still huge differences between universality and representativeness for netizen in cyberspace is not equal to citizen in reality. We can see from the perspective of netizen number that there are only $40 \%$ netizen of the whole population. Under this construction, the class of netizen in real life should be larger proportion of middle class, less numbers from the bottom and the top. Especially among citizen that take the largest proportion of population in reality, such as, farmers and migrant workers, netizen number is much smaller. Thus, cyber public will is not totally equal to public opinion; even some opinions do not stand for the thoughts of whole netizen community.

Cyber public opinion possesses the feature of authenticity. Due to the traction procedure of language and misgivings of social state, Public opinion from traditional way of expression often distorted, but Internet helps to weaken the social power of speakers and eliminates concerns. So that, cyber public opinion will be more authentic and direct sometime. However, we should not exclusive the one-sidedness and twisted opinion of Internet.

Cyber public opinion possesses the feature of timeliness. In the communication on cyberspace, there is no intermediate link, so every question can get feedback quite soon. This fast process used to complete with a long period of passing massages within different department, or maybe passed by newspapers and media. However, the short point of the fast communication shows that there is also no intermediate link to filter direct public opinion which might be not deliberate enough and too personal involved due to the lack of consideration. Certainly, the changes of cyber public opinion are heading to a more mature and rational direction.

Cyber public opinion possesses the feature of complexity. Complexity of cyber public opinion comes from the complexity of public opinion at the first place. While, the free form of Internet emphasis and enlarge this feature. There are rational and irrational, Jacobinical and gentle sides of public will, sometimes the voice is louder because of confident and validity, while it also might just be a louder voice. It is the same way of public voice from time to time. And this requires much more information and professional attitude to understand public opinion so that we can avoid impulsive and simple reaction.

Discrimination of cyber public opinion is to grasp it better. According to China's basic condition, the orientation of cyber public opinion is a support channel to reflection of public will. First of all, it is a support channel for system of public opinion. The institution of public will is people's congress and political consultative conference, they are the authority of public opinion according to constitution. Secondly, it is a support channel for mainstream media. Media like newspaper, magazine, broadcast and television is major tool to publicize public will. Surely the high bar, expensive cost and limited space not allow ordinary people to express themselves. As for Internet however, these problem can be solved. It is one form with lowest cost, fastest speed and most convenient so far. Cyberspace is also a very good method for these lower middle class who own certain amount of knowledge and artistic appreciation to express their thoughts. In a word, Internet is a advisable supplement for public opinion and will become more and more important. No matter which way, there are always complementary with each other. Thus, despite the advantage and disadvantage, we should select the refined and discard the crude to promote their development

\section{Instruction of Cyber Public Opinion}

It is government's responsibility to standard and leads the development of public opinion instead of just adjust public opinion passively. To mould a positive atmosphere of mainstream public opinion, the field of cyber public opinion need to be built, dominant right need to be grasped, leading ability online need to be enhanced, new technology should be applied, positive image propaganda need to be enlarged.

Cyber public opinion should have a certain standard. For the management of Internet, we should administrate it according to the operation of law, scientific method, and effectiveness by applying means as law, administration, 
economy, technology, ideological education, and self-discipline within industry and so on. So we can consist of a well-organized information dissemination channel with order. At the same time, self-discipline with industry should also be advocate to achieve this goal.

Cyber public opinion should be led properly. First, mainstream media need take this responsibility to leading cyber public opinion. As the major tool to adjust public opinion, there are a situation of disconnecting between network and mainstream media. It means whatever cause a hot discussion online cannot accept by mainstream media and vice versa. The conflicts between each other will not ease unless one of them takes the first step. When media insists the right direction of leading public opinion, it also needs to explore regular interaction in Internet at the same time. Besides, mainstream media can get more involved in cyberspace and become the front of public will discussion in virtual space. Second, make the full use of the leading power of social elites. Leaders, mangers, senior professional professors and scholars are a group people with rich social experiences, they are knowledgeable, mature-minded, understand laws, theoretically developed and critical. With the profound recognition in their profession study field, they have a better distinguish ability and all-round, objective and rational vision. Therefore, the join in of these social elites in cyberspace will help to publicize policy and lead public opinion. At last, hot topic need to be focused. Despite the vastness of cyberspace, there are a few very influential key website like portal and political website that affect on public opinion. Once they are under construction, we can achieve maximum results with little effort. With the endless topics online, hot topic always score people's attention. The focus of cyber public opinion is big event happen in domestic and overseas or living hood, social situation. For example, People's Net invites experts, scholars, and officers to discuss some of the hot spot to leading public will via mainstream and authentic voice. The question asked by netizen can be answer by one of the guests and draw much more attention onto the important topic on higher level such as the national economy and the people's livelihood. Therefore public can think in a retinal way.

\section{METHOD TO STRENGTHEN AND IMPROVE DEMOCRATIC CONSTRUCTION VIA INTERNET.}

The following part analyses how to strengthen and improve democratic construction using Internet.

\section{A. Create and Optimize the Cyber Environment for Government to Communicate with Residents}

The process of govern the society is actually the process of gathering, processing and dealing information. The participation of Internet user provides a new condition for government to extract information. The advice is to establish an communicable cyber environment that netizen can involved in the participation, discussion of government and political affairs as well as other major and important matters like government respond, division rectifying and improving to optimize the mechanism of communication between government and citizen. By reasonable dialogue between public and government, questions from public can be answered. Then two parties can face challenges together, resolve social conflicts and issues and contribute to harmonious atmosphere in the society.

\section{B. Allowing Public Right to Information by Increasing} Publication of Government Information in Cyberspace

Publication of information is the precondition of democratic supervision, thought the development of Internet technology, the precondition can be achieved. While, as for now, information provided by official website is far more than enough for public supervision. The advice is to plan and public the detail information, such as project plan, budget, receipt of budget, progress of work, duty of individuals (especially for leaders and officers), the handling of big event on major website, so people have enough information to exercise their power of supervision.

\section{Allowing People's Right to Participation by Seeking Public Opinion Online with Sensitive Matters and Strengthen Policies and Regulations}

The construction procedure of seeking public opinion online before promulgate policies and regulations is on its way now. However, due to the short amount of time, the survey cannot cover large population. Therefore, there are perfunctory situation that many of procedure just a form instead of gathering public opinion. Seeking public opinion via Internet is propitious for understanding livelihood, convey public will, and improve the scientificalness of decision making. The advice is to leave abundant time to carry out the survey online to gather public opinion before promulgate policies and regulations, then seriously modify and perfect proposal according to feedback.

\section{Establish Mechanism of Post, Follow-up, Regular Communication Online to Make Sure the Fully Expression of Public Opinion}

Take the event of "ask question to Premier Wen" and "the obstruction of the Olympic Game's torch passing" as examples, every time when influential event happens, there are a lot of post and follow-up online. It means that Internet user have a great passion about what happened in reality. Comparatively speaking, there are only short amount of post online from government and officers. The advice is government should post the big event online for netizen to express their opinion, at the same time, the follow-up and communication also need to be done properly so public opinion and question can be noticed. Furthermore, government can organize pint-sized meeting with netizen, and send some officers like governor of a province, secretary to communicate with them directly, by this way, it is good for neutralize conflicts, gathering public opinion and close relationship with citizen.

\section{E. Making sure of People's Superintendence by Enacting Policies and Regulations to Analyze and Process Cyber Public Opinion}

The fast speed, low cost, and effectiveness of cyber supervision provide discipline inspection division and judicial department abandon resources and leads for anti-corruption. The advice is to enact corresponding policies and regulations to standardize online opinions and supervision, and then give timely feedback. Therefore we can convey correctly determination and guidance from party and government work on close relationship with residents and promote the development of homonymous society.

As for the unrestricted expression of (political) opinion, anonymity in Internet, and differences between knowledge, cultural background, moral standard, values of individuals, 
there are many negative problem emerging when Internet play a positive role in democratic construction. Thus, it might cause several chain reaction that against the development of society, such as spread rumors that harmful to the country, ill values, Internet mass hunting that against law, Internet rabbles that use keyboard as their weapon, Internet KUSO and gray culture. To exploit the feature and technology of Internet to develop socialist democracy need to strengthen the control and management of cyberspace. The development of Internet cannot split away from the development of reality, social and moral standards and turn into the stage of anarchism, absolute liberalism, and individual interest maximization.

\section{CONCLUSION}

The development of Internet provide new technology, platform and prospective of democratic construction, as well as the challenge predicament. How to exploit this technology to pushing society move forward, foster strengths and circumvent weaknesses in democratic freedom and construction is the severe task we are facing at the moment. It requires ideology changes of governing pattern and idea, also the completion of Internet technology to allow more people to access the Internet in various ways, and requires achieve stronger growth of economy and common wealth to provide material guarantee for participation, also requires farther purify Internet environment, decrease the amount of ill information, and boost users' resolving ability of information. Therefore gain a prospective future of democratic construction via Internet.

\section{ACKNOWLEDGEMENT}

This paper is supported by Foundation of Philosophy \& Social Science of AH Province, China(AHSK11-12D336) and Teaching \& Research Foundation on Higher Education of AH Province, China(2012jyxm521).

\section{REFERENCES}

[1] Peng Peng. Mysterious Gate of Cyber Democratic Construction [J] Nanjing: School Paper of Nanjing political University, 2003.

[2] Jianmin Cao. The Legal Study of Socialism with Chinese Characteristics. The Democratic Power of twenty sites, 2009(7).

[3] Huaxin Zhu, Jiangchun Hu, Wentao Sun. the analysis report of Internet public sentiment in China, 2007.

[4] Haiguang Xie. Generality of ideological/political work and Internet. Fudan University Press, 2000/11.

[5] Yinzhu Li. Ponderation and exploration of inner-Party democracy development. China Economy Press, 2009/05.

[6] Jiangguo Wang. Study of Inner-Party Democracy in New Times. China Social Science Publishing House, 2008/12.

[7] Xiaoyu Tian. Ponderation of Promoting Socialist Democratic Development. Intellectual Property Press, 2010/11/1.

[8] Jingtao Hu, Waving the flag of Socialism with Chinese Characteristics, fights for builds a well-off society in an all-round way. [M]. People's Press, 2007.

[9] Chunli Zhao. The Study of Cyber Democratic Development. Economic science press, 2011/1.

[10] Jun Li. Facing the Political Democratic Construction in New Century. Sichuan University Press, 2009/4.

[11] Shucun Zhen. Democratic Opportunities and Challenges Brought by Internet [J]. Political Study,2001.

[12] John W. Maynor .Critical Review of International Social and Political Philosophy .No.3,2009.

[13] Guoyou Zhang,Yuting Pan,Yikui Ge.Cope with Internet Public Relation Crisis of Enterprise Positively.The Ninth Wuhan International Conference on E-Business-e-Business Track[C],2010,PP606-611
[14] Zhang Guoyou , Zhang Yueqiang, and Wang Yiping.On the Reason for the Innovation of Business Model and the Mechanism of Transformation. The 2009 International Symposium on Information Processing[C],2009,PP377-380.

[15] Zhang Guoyou, Zhang Yueqiang, Liyu. The Reformation of the C2C Electronic Commerce Transaction.2008 International Conference on Management of E-Commerce and E-Government[C],2008,PP104-108.

[16] Zhang Guoyou. Time Identification of Electronic Documents. ICMeCG2011[C].2008,PP150-153 